\title{
Asphalt Pavement Material Improvement: A Review
}

\author{
Mohamed Sulyman, Maciej Sienkiewicz, and Jozef Haponiuk
}

\begin{abstract}
The recycling of solid industrial wastes (SIW) such as waste rubber tires and plastics will not only solve the global environmental problem of these SIW but also act as very promising modifiers for the improvement of engineering characteristics of the asphalt pavement material.

The present work was concerned with assisting the interested readers to be familiarized with the paving material asphalt-modifiers obtained from SIW by providing historical perspective on its first invention and development. The paper has also provided highlights on common processes of asphalt mixture production. It was also worth mentioning that there are two asphalt production technologies: the warm mix asphalt (WMA) and hot mix asphalt (HMA) technologies, and the various advantages of using each one.

Additionally, the paper has provided the reader with an overview of a number of case studies which were conducted by scientists and researchers for serious attempting to reach development and capturing significant properties of incorporating SIWs in civil engineering represented by scarp tires in form of crumb rubber (CR), plastics (polymers) in their different forms.
\end{abstract}

Index Terms-Asphalt, crumb rubber tires, waste plastics.

\section{INTRODUCTION}

Asphalt is known as brittle and hard in cold environments and soft in hot environments. As a pavement material, it is characterized with a number of failures represented by the low temperature cracking, fatigue cracking, and the rutting (or permanent deformation) at high temperature, causing its quality and performance in pavement of roads to decrease [1]. Though, it has been historically the most popular paving material for roadways.

Any improvement in service life of road pavements will be off course of a great economical advantage and any modifications of asphalt are attempts to extend the service life and improve the performance of asphalt pavements [2].

The global problem with landfill disposal of automobile tires and plastics can only be solved by the feasible option left, and that is recycling and utilization of the recycled products. It is thought that the application of recycled automobile tires and plastics will not only solve the environmental of these industrial solid wastes problem but also act as very promising modifiers for the improvement of asphalt pavement material [2]. Rokade S., (2012) has investigated the utilization of waste rubber tires and waste plastics in pavement of flexible highway, as a result he has concluded that the project is not only to improve the engineering properties of asphalt, but also allows us to collect

The manuscript revised September 24, 2013; revised March 3, 2014.

The authors are with The Polymer Technology Department, Chemical Faculty, Gdansk University of Technology, Poland (e-mail: mohamedsuliman2000@yahoo.com, Corresponding author: Mohamed Sulyman). modifier raw materials (plastics or crumb rubber) at low costs and provide a solution to the ecological menace imposed by the increase disposal of waste tires and plastics [3].

\section{History OF AsPhalt Mix InVENTION}

The actions of modifying the asphalt paving material have begun long time ago and hopes were sought initially in earlier experiments of incorporating natural rubber with asphalt in $1840 \mathrm{~s}$, in order to capture the flexible nature of rubber in a longer lasting paving surface. Unfortunately, the aim was difficult to attain and the asphalt-rubber formulas did not bring a benefit, and the result was a modified asphalt pavement material that was more costly and shorter in service life than ordinary asphalt [4].

During 1900's, the technique of using asphalt in pavements was first used on rural roads to prevent the rapid removal of dust from water bound macadam caused due to fast growth of automobiles. At initial stages, heavy oils were used as a dust palliative. The estimations of the exact quantity of the heavy oil in the mix were performed by an eye judgment. The $1^{\text {st }}$ formal method of mix design was called Habbard field method, which was actually developed on sand asphalt mixture. One limitation of this method, however, was the inability of dealing with mixtures with larger sized aggregate particles than dust. Latter, in 1927, a project engineer of California department of highways named Fransis Hveem has developed the Hveem stabilometer. He did not have any previous experience on judging the required mix from its colour, hence he decided to measure various mixture parameters to find the optimum quantity of asphalt. He had used the surface area calculation concept, (which was already in use in that time), to estimate the quantity of asphalt actually required. Then, just before the World War-II, Bruce Marshall has developed the Marshall testing machine which was adopted in the US Army Corps. of Engineers in 1930's and subsequently modified in 1940's and 50's [5].

The real evolution of mix started exactly in the 1960s, when a successful formulation was discovered by a bureau of public roads employee named Charles H. MacDonald while traveling across the country inspecting highway material sources and had a crack on his mobile trailer's roof. To fix the crack, he ran many attempts of using asphalt and did not succeed. He latter thought he could solve the crack if he incorporated rubber [6]. And thus he experimentally tried the addition of ground tire rubber to hot liquid asphalt, and only after thoroughly mixing them and allowing it to react for a period of time, new material properties were obtained. This new product material captured beneficial engineering properties [7]. The asphalt was absorbed by the rubber particles, which swelled in size at higher temperatures allowing for greater concentrations of liquid asphalt contents in pavement mixes. By 1968, the Arizona department of transportation in USA began numerous and diverse research 
and development projects involving asphalt-rubber. By 1975, CR was successfully incorporated into HMA [8]. Latter, in the mid-1980s, the Europeans began the development of newer polymers and additives for use in bitumen binder modification [9].

\section{PROCESSES OF ASPHALt MiX with RubBER TIRES}

Production of asphalt mixtures with tire rubber in form of $\mathrm{CR}$ is usually established by mainly one of two common ways; the first one is called the wet process where rubber particles are mixed with asphalt at elevated temperature prior to mixing with the hot aggregates. The second type is called dry process, where rubber particles replace a small portion of the mineral aggregate in the asphalt mix before the addition of the asphalt [10].

The main differences between these processes include size of rubber; in the dry process rubber is much coarser than wet process rubber, amount of rubber; the dry process uses rubber 2 to 4 times as much as the wet process, function of rubber; in the dry process the rubber acts more like an aggregate but in the wet process it acts more like the binder, and finally the ease of incorporation into the mix; in the dry process no special equipment is required while in the wet process special mixing chambers, reaction and blending tanks, and oversized pumps are required [11].
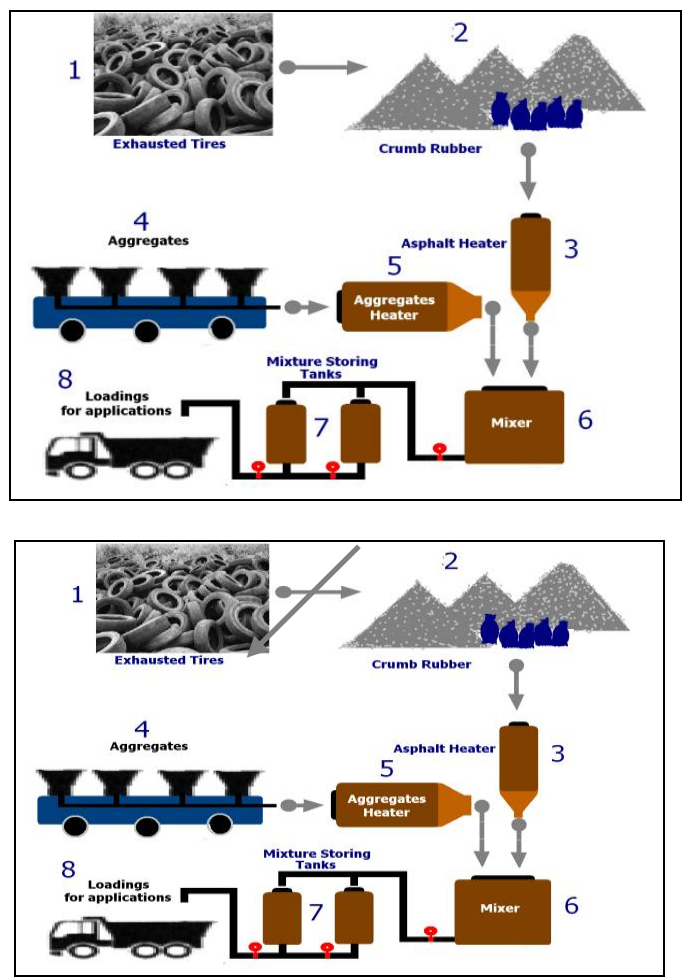

Fig. 1. (A-Up) Rubberized asphalt mixture by wet process, (B-Below) Rubberized asphalt mixture by dry process [10]. Note: the arrows make the differences between the two figures.

Explanation of numbers of top figures: 1- Whole tires, 2- Powder of waste tires, 3- Heat of Asphalt, 4- Aggregates, 5- Heat of aggregates, 6-Mixing bitumen with aggregates, 7Storage of mixture, 8- Loading \& transportation to the site.

\section{A. The Wet Process}

The binder produced from wet process, or the McDonald process, is called asphalt rubber. It has been defined by American Society for Testing and Materials (ASTM) as "A blend of asphalt cement, reclaimed tire rubber, and certain additives in which the rubber component is at least $15 \%$ by weight of the total blend and has reacted in the hot asphalt cement sufficiently to cause swelling of the rubber particles" [12]. In wet process, asphalt is blended with a crumb rubber modifier (CRM) in a specialized blending unit at elevated temperatures $\left(190-225^{\circ} \mathrm{C}\right)$ for a minimum of $45 \mathrm{~min}$ to promote the chemical bonding of the components. During the blending process, CR swells and softens with the asphalt. This reaction is influenced by the blending temperature, the time the temperature remains elevated, the type and amount of mechanical mixing, the size and texture of CR, and the aromatic component of the asphalt. CRM typically ranges from 18 to $22 \%$ by weight of the asphalt. Extender oils are sometimes used to reduce viscosity and promote workability of the asphalt rubber as well as to increase the compatibility between the asphalt and CR. The diagram in Figure 1 shows production of asphalt rubber mixes using the wet process [10]. Asphalt rubber mix is used primarily in open graded and gap graded HMA. It is also used in spray applications for seal coats and pavement interlayers and as a crack sealant [13].

\section{1) Case studies}

According to laboratory tests concerning the application of wet process of asphalt rubber mix [14], [15], it was concluded that rubber particles retain a larger proportion of the asphalt compared with the aggregates, suggesting an interaction between asphalt and rubber. In another laboratory study by Pais et al., (2001) [16], they have reported that tire rubber inclusions can modify a conventional HMA in terms of a flexural fatigue life, since mixtures which include rubber treated using different processes (cryogenic or ambient) have shown greater fatigue life than conventional mixtures regardless of the void content. The last may vary from one mixture to another for the same category of asphalt. The examination of tensile strength characteristics of a dense asphalt macadam (DAM) mixes with CR by Punith et al. (2002) [17], have revealed improved characteristics in terms of Marshall stability and indirect tensile strength at various temperatures under soaked and unsoaked conditions. Both of these properties increased as the tire rubber percentage increased. For unsoaked conditions in particular, the indirect tensile strength was higher compared with that of the soaked samples, while it was decreased as temperature increased. Additionally, at high temperatures tensile strength was almost the same for both, the rubberised DAM mixture and the virgin asphalt; thus rubberised asphalt mixtures are expected to have a longer life than the conventional DAM. Another study was carried out by Rahman et al. (2004) [18] on dense, graded rubberised asphalt mixtures produced using the wet process, and containing (3-5)\% CR by total aggregate weight, showed that those mixtures are more susceptible to moisture damage compared with conventional mixtures while their stiffness reduced by (30-75)\% depending on the $\mathrm{CR}$ content. However, when fine rubber particles $(<1.0 \mathrm{~mm}$ size $)$ are added to asphalt mixtures, they have produced mixtures with improved characteristics in terms of stiffness, resistance to permanent deformation and rut, whereas particles of such gradation were more effective 
than coarser ones as far as rutting resistance was concerned. In 2005, Tortum et al. have studied the effects of tire rubber and aggregate gradation, mixing and compaction temperature, tire rubber and binder ratio, and mixing time on bituminous mixtures [19]. They have concluded that for specific conditions, rubberized asphalt mixtures have performed better than the conventional mixture. A pilot project was conducted in Taiwan [10], [20]; two test sections were studied, the first section had a gap-graded design while the second had an open-graded design. The incorporation of $\mathrm{CR}$ showed that these mixtures can have equal or even better field density and smoothness than conventional mixtures. Field measurements and visual observations indicated that these mixtures performed well. In fact, the $\mathrm{CR}$ addition technique to the asphalt using wet process as a test project was conducted in Florida by Choubane et al. in 1999 [21] and was evaluated after 10 years. Results showed that crack resistance of surface mixtures was improved; another test project conducted using dry process (described in the following section) resulted in more cracked areas. Since then, the use of rubberised asphalt has become more popular given the fact that it produces pavements with reduced noise pollution. This was first noted in Belgium in 1981, in an asphalt rubber hot mix called "Drain Asphalt". Other countries, where rubberised asphalt mixtures have been used and where equal or lower traffic noise reduction levels have been reported include Canada (1991), England (1998), France (1984),Germany (1980), Austria (1988) and the Netherlands (1988). As a result, many states of the USA and other countries around the world have continued to use such mixtures [15], [22].

\section{B. The Dry Process}

As aforementioned, in the dry process, $\mathrm{CR}$ is added to the aggregate in a hot mix plant operation prior to adding the asphalt. There is relatively little reaction between the asphalt and $\mathrm{CR}$ in the dry process. In essence, CR replaces a portion of the aggregate. The dry process can be used in dense graded, open graded, or gap graded HMA. The most commonly used dry process was developed and patented in the late 1960s in Sweden and in 1978 in USA. The performance of pavements using this process has met with mixed reviews and, as a result, the dry process is not widely used for modifying asphalt pavements [13].

\section{1) Case studies}

Fernandes et al., (2002) in one of their researches, have concluded that rubber in rubberised asphalt mixtures, produced by dry process, have increased the elasticity of the mixture; it could enhance the bonding between binder and aggregates resulting in an increase in fatigue life, and resistance to rutting, and could lead to a reduction of the thermal and reflecting cracking of these mixtures [23]. In concern with dry process, a number of scientific reports [24], [25] have revealed that the control of rubber particles and asphalt interaction could not be done in an easy way since there was immediate mixing between aggregates and asphalt. When these mixtures were established correctly, such pavements were better for icy road conditions. Recent studies have also concluded that during mixing and transportation, rubber reacted with asphalt, changing the properties, shape and rigidity of the rubber; as a result the performance of the asphalt mixture have been changed [10], [15], [26]. Studies on the effect of moisture on the mechanical properties of rubberised asphalt mixtures have shown that stiffness was reduced by the incorporation of rubber particles $(2-8 \mathrm{~mm})$, and that stiffness was decreased with increasing rubber content. Reduction of stiffness was due to the creation of voids by rubber particles in the mixture; as a result more water penetrated into the matrix during saturation giving a weaker structure. For rubberised asphalt mixtures, resistance to permanent deformation was found to decrease compared with the control mixtures, in terms of strain rate, because of the moisture conditioning; however, the presence of rubber in the mixtures resulted in an increase in fatigue performance before moisture conditioning. Therefore, rubberised asphalt mixtures would result in better mechanical characteristics than the control mixtures during the early stages. It was reported that when rubberised asphalt mixtures exposed to moisture for long periods, this enhanced performance would be reduced [16]. Another study was carried out by Kettab and Bali (2004) indicating that when rubber with particle size higher than $2 \mathrm{~mm}$ was added to asphalt mixtures, the compaction and strength characteristics were improved as the rubber fills the existing voids within the granular skeleton [27]. Studies on CR asphalt mixtures produced by dry process showed that the addition of rubber at (10-15)\% (by weight of the asphalt) caused a reduction in penetration into bitumen and softening point, while viscosity increased with CR content and decreased as temperature was elevated [25]. According to Fernandes et al. (2002), rubberised dense asphalt mixtures has resulted in lower Marshall stability values than the virgin asphalt, while flowability increased with the increase of rubber content. These mixtures, however, did not meet the requirements of the Brazilian standards [22], [23]. Besides, rubberised asphalt mixtures have also resulted in lower values of resilient modulus and tensile strength compared with virgin asphalt, while gradation of the rubber have been found to have a small influence on the tensile strength. Reduction in resilient modulus have been higher as the size and content of rubber increased, and mixtures with fine rubber particles ranging between $0.15-1.18 \mathrm{~mm}$ in size at up to $2 \%$ (by weight of the total mix) have shown very good performance in terms of rutting resistance [22]. In Greece, a study was also conducted in concern with rubber-modified asphalt mixtures using dry process. However, the obtained results of the study did not meet the requirements of Hellenic Standards when mixtures contained rubber at $>1 \%$ (by weight of the aggregates) [28].

Conclusively, although the dry process has the advantages concerning the lower costs involved and the higher amount of rubber to be used, the process did not greatly attract researchers due to the irregular performance of some experiment sections built with it. Therefore, researchers have focused to a great extent on the wet process which usually present more satisfactory results.

\section{CRumb Rubber Tires}

CR is usually defined as rubber having a particle size of 9.5 $\mathrm{mm}$ (3/8 inch) or less. They can be classified into four groups as follows: coarse, $9.5-6.3 \mathrm{~mm}$; mid range, $2-1 \mathrm{~mm}$; fine, 
$0.4-0.2 \mathrm{~mm}$; and superfine, $0.15-0.075 \mathrm{~mm}$. $\mathrm{CR}$ is commonly obtained by using either of these processes [29].

\section{A. Ambient Ground Rubber}

It is obtained by shredding and grinding (milling) the tire rubber at or above ordinary room temperature. This process produces a sponge-like surface on the granulated rubber crumbs which have considerably greater surface area for a given size particle than do cryogenically ground rubber particles. Increased surface area increases the reaction rate with hot asphalt.

\section{B. Cryogenic Ground Rubber}

This type of ground rubber is obtained by grinding (milling) the tire rubber at or below the embrittlement temperature of the rubber, usually achieved by the use of liquid nitrogen. This process produces clean flat surfaces which, in turn, reduce the reaction rate with hot asphalt. According to the research by the Australian Road Research Board, this process produces undesirable particle morphology (structure) and generally gives lower elastic recovery compared to the ambient ground rubber (see Table I and Table II).

TABLE I: CHARACTERISTIC OF AMBIENT AND CRYOGENIC GROUND RUBBER [10], [30], [31]

\begin{tabular}{|l|l|l|}
\hline \multicolumn{2}{|c|}{ RUBBER [10], [30], [31] } & Cryogenic \\
\hline $\begin{array}{l}\text { Operating } \\
\text { temperature }\end{array}$ & Ambient & Below- $80{ }^{\circ} \mathrm{C}$ \\
\hline $\begin{array}{l}\text { Size reduction } \\
\text { principle }\end{array}$ & $\begin{array}{l}\text { Cutting, tearing, } \\
\text { shearing }\end{array}$ & $\begin{array}{l}\text { Braking cryogenically } \\
\text { embrittled rubber pieces }\end{array}$ \\
\hline $\begin{array}{l}\text { Particle } \\
\text { morphology }\end{array}$ & $\begin{array}{l}\text { Spongy and rough, high } \\
\text { specific surface }\end{array}$ & $\begin{array}{l}\text { Even and smooth, low } \\
\text { specific surface }\end{array}$ \\
\hline $\begin{array}{l}\text { Particle size } \\
\text { distribution }\end{array}$ & $\begin{array}{l}\text { Relatively narrow } \\
\text { particle size } \\
\text { distribution, only } \\
\text { limited size reduction } \\
\text { per grinding step }\end{array}$ & $\begin{array}{l}\text { Wide particle size } \\
\text { distribution } \text { (ranging } \\
10 \text { mm to } 0.2 \mathrm{~mm} \text { ) in just } \\
\text { one processing step }\end{array}$ \\
\hline Maintenance cost & Higher & Lower \\
\hline $\begin{array}{l}\text { Electricity } \\
\text { consumption }\end{array}$ & Higher & Lower \\
\hline LN2Consumption & N/A & $\begin{array}{l}\text { No.5-1.0 kgLN2 per kg } \\
\text { tire input }\end{array}$ \\
\hline
\end{tabular}

TABLE II: COMPARISON BETWEEN AMBIENT AND CRYOGENIC GROUND

\begin{tabular}{|l|l|l|}
\hline \multicolumn{2}{c}{ RUBBER [10], [30], [31] } \\
\hline Physical property & Ambient Ground & Cryogenic Ground \\
\hline Specific gravity & Same & Same \\
Particle Shape & Irregular & Regular \\
Fiber Content & $0.5 \%$ & Nil \\
Steel Content & $0.1 \%$ & Nil \\
Cost & Comparable & Comparable \\
\hline
\end{tabular}

A case study based on laboratory investigations conducted on the properties of CRM asphalts as a function of CRM processing method (ambient vs. cryogenic) [32]. A CRM asphalt was produced and artificially aged through an accelerated aging process. The results from this study have indicated that the ambient CRM generally was found to be more effective on producing the CRM asphalts that were more viscous and less susceptible to rutting and cracking. From test results, the following conclusions were also drawn: i) The ambient CRM have resulted in higher viscosity values than the cryogenic CRM at the same percentage usage, and this was attributed to the increased surface area and irregular shape of the ambient CRM, ii) The ambient CRM was found to be more effective on producing the CRM asphalts that were less susceptible to rutting at high pavement temperatures, iii) the difference between ambient and cryogenic CRM was not found to have a significant effect on the $\mathrm{G}^{*}$ sind of the CRM asphalts at the 5\% level. (the higher $\mathrm{G}^{*} /$ sind values indicate that the binders will be less susceptible to permanent deformation at high pavement temperatures), iv) the CRM binders produced with ambient CRM showed a better resistance on low temperature cracking than those with cryogenic CRM, v) the processing methods (ambient vs. cryogenic) used to manufacture CRM were not found to have statistically significant effects on change in the m-value.

\section{Hot-MiX AND WARM-MIX TECHNIQUES}

It was reported that about 299 million scrap tires are generated every year in the USA. And many state regulations penalize landfill disposal of these materials [33]. The incorporation of the scrap tires in the asphalt binder is established by converting the scrap tire to CR. As mentioned previously, this $\mathrm{CR}$ will be added to asphalt before adding the asphalt to aggregate using the common wet process to produce HMA.

\section{A. Case Studies}

There has been a steady and increasing interest in using of crumb rubberized binders in HMA pavements in the Unites States and other countries [34] (Fig. 2), due to the conclusions drawn by some investigation studies which have indicated that rubberized binders could produce asphalt pavements with a decreased traffic noise, reduced maintenance costs and improved resistance to rutting and cracking [35]-[37].

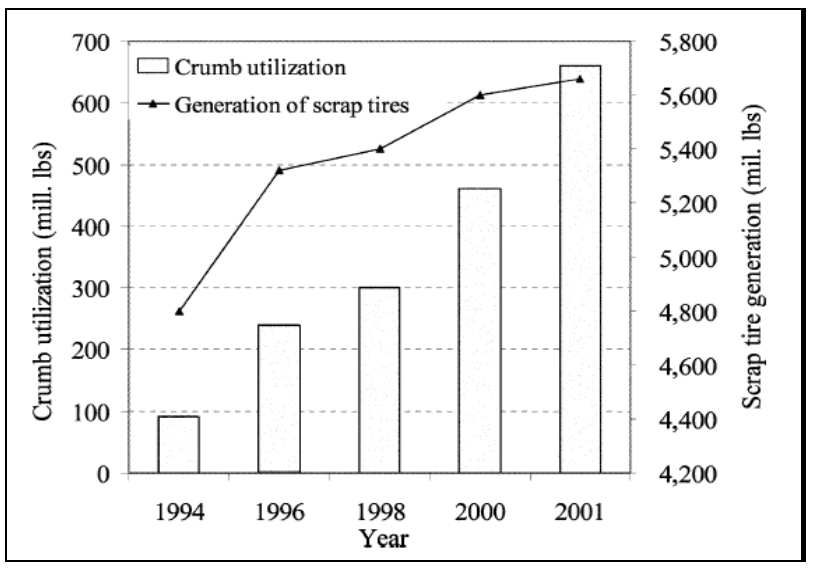

Fig. 2. Scrap tire utilization alternatives, [29], [38].

However, the increase of rubber content unfortunately produces an increase in flexibility, and the incorporation of the rubber itself to the virgin asphalt binders can reduce the indirect tensile strength of modified mixtures [39]. Production of HMA at high temperatures can result in undesirable high energy consumption [40], greenhouse gas (GHG) emissions, fumes and odors [41], deteriorating inhabitants locations. In addition, the high temperature requirement results in shorter paving seasons, and longer cooling periods [42].

Alternatively, introducing warm mix asphalt (WMA) is known to provide decreased optimum mixing and compaction temperatures of the rubberized mixes and 
expected to be comparable to those of conventional mixes. WMA was first originated in Europe in the mid ' $90 \mathrm{~s}$. WMA is mixed and compacted at temperatures lower than these of conventional HMA. Typically, the mixing and compaction temperatures of WMA range from 100 to $140^{\circ} \mathrm{C}$ in comparison to 150 to $180^{\circ} \mathrm{C}$ for HMA [43], [44]. It has been proven that WMA techniques can provide a number of benefits due to the lowered production temperatures. Although benefits can vary depending on the specific warm mix additive being used, the potential benefits of WMA techniques are summarized as follows [44]: i) improved compaction of asphalt mix, especially stiff mixes; ii) increased use of reclaimed asphalt pavement; iii) extension of paving seasons; iv) night paving and longer haul distances; v) reduction of asphalt oxidation for prolonged pavement life; vi) less fuel consumption and energy costs; vii) reduction of heat, odor, smoke and GHG at the plant.

However, in WMA some concerns have been reported regarding the durability of these mixtures due to the reduced mixing and compaction temperatures used in production. Several studies [45]-[50] have been conducted to determine the applicability of WMA techniques to paving operations and environmental conditions compared to the traditional HMA. One of the main concerns is the increased susceptibility of WMA to permanent deformation. For example, it is possible that the asphalt binder in WMA may not sufficiently harden at relatively low production temperatures and, hence, may develop higher post-construction densification or distortion under early-age traffic. Another concern is that WMA may have an increased tendency to moisture-induced damage. In WMA, aggregates are heated to relatively low temperatures and therefore may not thoroughly dry before they are mixed with the asphalt binder; thereby reducing the amount of binder absorbed into the aggregates.

Due to the different mechanisms of WMA preparation techniques, physical and chemical properties of the mixture can be altered resulting in different short-term and long-term mechanical behaviors of the final product. Several researchers have evaluated the performance of WMA with regards to various physical pavement factors. For instance, in 2007, Prowell et al. have reported that similar performance for the emulsion-based WMA (EvothermTM ET) and HMA surface mixes with the PG 67-22 base asphalt binder. However, laboratory tests indicated an increased moisture damage potential for WMA [45].

Another study have been carried out by Wasiuddin et al. (2007) who compared the performance of WMA with Sasobit and Aspha-Min additives and found that Sasobit decreased the WMA rutting potential more significantly than the Aspha-Min additive. The addition of Sasobit could increase the high temperature grading of the asphalt binder [46]. Latter, Mallick et al. (2008) have investigated the feasibility of using a WMA additive, Sasobit, with $75 \%$ reclaimed asphalt pavement (RAP) for producing a base course at a lower temperature and found that the performance of WMA with RAP was dependent on the stiffness of the combined (rejuvenated) binder in the mixture [47]. Moreover, Lee et al. (2008) have investigated the performance properties of WMA binders (Aspha-Min and Sasobit) containing aged binder. They found that WMA additives might not have positive effects on the resistance to fatigue and thermal cracking when recycled binder was used in WMA [48]. Xiao et al. (2010) have evaluated the rut depth, weight loss, and gyration number of dry and conditioned specimens containing warm mix additives (Aspha-Min, Sasobit, and EvothermTM 3G). The results indicated that the aggregate source affected the mix rutting potential most significantly, regardless of the additive and moisture content [49]. A series of studies have been conducted at the National Center for Asphalt Technology (NCAT) to evaluate the laboratory performance of asphalt mixtures with different warm mix additives, EvothermTM 3G, Sasobit, and Aspha-min [50]-[53]. Their major findings from several reports are summarized herein: i) adding WMA additives improved the compactability of the mixtures, ii) application of either warm mix process did not affect the resilient modulus or increase the rutting potential of asphalt mixtures compared to control mixtures having the same PG binder, iii) lower mixing and compaction temperatures for WMA may increase the potential for moisture damage. An anti-stripping agent may be added to yield an acceptable tensile strength ratio, vi) based on the compaction and rutting results, a minimum field mixing temperature of $135^{\circ} \mathrm{C}$ and a minimum field compaction temperature of $121^{\circ} \mathrm{C}$ is recommended.

\section{REuSE OF SIW in ASPHALt PAVEMENTS}

One of the major environmental concerns worldwide is the landfill disposals of SIW. Disposals of expired automobile tires and plastics randomly are considered as one of those major causes damaging our ecosystem and posing health problems to all types of life alarmingly. Annually, large volume of tires become exhausted and thrown as wastes frequently seen on the sides of the roads and highways. Also, plastics have been habitually mixed with our municipal solid wastes and sometimes disposed over land areas. And both, in terms of their chemical characteristic represented by their chemical bonds, are very durables and non-biodegradables. As this action continuous to occur, this also calls for implementing very effective management worldwide. The aim is to facilitated technical plans based on control of the toxins resulting from decomposition mostly by means of recycling and reuse of such substances. As a result, many studies and researches have focused on reusing and recycling waste rubber tires and plastics in civil engineering such as in developments and improvements of asphalt surfacing material.

\section{A. Asphalt Binders Containing Plastics: Case Studies}

TABLE III: EXAMPLES OF THERMOPLASTICS AND THERMOSETTING

\begin{tabular}{|l|c|}
\hline \multicolumn{2}{|c|}{ MATERIALS } \\
\hline Thermoplastics & Thermosetting \\
\hline Polyethylene Teryphthalate (PET) & Bakalite \\
\hline Polypropylene (PP) & Melamine \\
\hline Polyvinyl Acetate (PVA) & Polyester \\
\hline Polyvinyl Chloride (PVC) & Polyuryurethane \\
\hline Polystyrene (PS) & Urea - Formaldehyde \\
\hline Low density polyethelene (LDPE) & Alkyd \\
\hline High density polyethylene (HDPE) & \\
\hline
\end{tabular}


Polymers modifiers typically involved in construction of flexible road pavement include plastics, elastomers and fibers. Plastics (polymers) can be subdivided into two main types depending on their behavior when exposed to heat; one type is called thermosetting which once formed, it can not be softened or redesigned by applying heat, in other wards it dose not withstand heat. The other type is called thermoplastics which can be shaped and designed in new models by use of heat. Examples of those materials that form either one are shown in Table III, and their source of waste plastic generation in Table IV [54].

TABLE IV: SOURCES OF WASTE PLASTIC GENERATIONS

\begin{tabular}{|l|l|}
\hline Waste Plastics & Source \\
\hline $\begin{array}{l}\text { Polyethylene } \\
\text { Teryphthalate (PET) }\end{array}$ & Drinking water bottles ... etc. \\
\hline Polypropylene (PP) & $\begin{array}{l}\text { Bottle caps and closures, wrappers of detergent, } \\
\text { biscuit, vapors packets, etc.. }\end{array}$ \\
\hline $\begin{array}{l}\text { Polyvinyl Chloride } \\
\text { (PVC) }\end{array}$ & $\begin{array}{l}\text { Mineral water bottles, credit cards, toys, pipes \& } \\
\text { gutters; electrical fittings, furniture, folders and } \\
\text { pens, medical disposables ... etc. }\end{array}$ \\
\hline $\begin{array}{l}\text { Polystyrene (PS) } \\
\text { Yoghurt pots, clear egg packs, bottle caps, } \\
\text { foamed polystyrene: food trays, egg boxes, } \\
\text { disposable cups, protective packaging ... etc. }\end{array}$ \\
\hline $\begin{array}{l}\text { Low density } \\
\text { polyethylene(LDPE) }\end{array}$ & $\begin{array}{l}\text { Carry bags, sacks, milk pouches, bin lining, } \\
\text { cosmetic \& detergent bottles. }\end{array}$ \\
\hline $\begin{array}{l}\text { High density } \\
\text { polyethylene(HDPE) }\end{array}$ & Carry bags, bottle caps, house hold, ... etc. \\
\hline
\end{tabular}

A plastic is one type of many materials that most commonly used to modify the engineering properties of binders such as asphalt. In this regard, efforts have been centered on polymers applications on the improvements of asphalt pavement material through a number of studies conducted by researchers. An early study concerning the effect of wax in asphalt has been conducted [55]. According to the results and data obtained, the researchers concluded that the addition of $4 \%$ ethyl vinyl acetate (EVA), $6 \%$ styrene-butadiene-styrene copolymers (SBS) or $8 \%$ resin in the waxy asphalt could actually lead to reduction in i) susceptibility to high temperatures, ii) bleeding at high temperature and iii) brittleness at low temperature of the mixes. Successful studies conducted by Justom .G. and Veeraragavan A. (2002), at the transportation engineering center of Bangalore University in India revealed that processed plastic bags as an additive when blended with asphalt concrete, it was found that penetration and ductility values of such modified asphalt was decreasing with the increase in proportion of the processed plastic bags additive, up to $12 \%$ by weight as compared to an ordinary asphalt [56]. In 2007, T. Awwad Mohammad and Sheeb Lina`s study have investigated the improvement of asphalt properties when it was mixed with polyethylene (PE). Their study have been also carried out to determine the best type of PE to be used and its proportion. HDPE and LDPE were two types of PE added to coat the aggregate. Data analysis proved that grinded HDPE polyethylene modifier provided better engineering properties. The recommended proportion of the modifier was $12 \%$ by weight of asphalt content. It was also found to increase the stability, reduce the density and slightly increase the air voids and the voids of mineral aggregate [57].
In regard to the application of LDPE, another study on recycling of $\mathrm{CR}$ and LDPE blend on stone matrix asphalt SMA by use of dry process was conducted [58]. The study was planed to reduce pollutions from waste tires disposals and to investigated the benefits of stabilizing the so-called SMA using CR and LDPE in $15 \%$ and $30 \%$ by weight of asphalt respectively. SMA had an optimum dosage of the additives of a combination of $30 \%$ (combined combination with $30 \%$ CR \& 70\% LDPE) by weight of the asphalt. Results of tensile strength test has found its ratio values to be in the range of $(85-94) \%$ which was more than $85 \%$ as specified for a SMA mixture, while the compression strength test values were found to be in the range of $(1600-4000)$ $\mathrm{kg} / \mathrm{cm}^{2}$ which has improved longevity. Generally, the results revealed that the addition of CR \& LDPE to SMA using dry process could improve the engineering properties of SMA mixture, and the rubber content has added a significant effect on long term performance.

Certain polymers called elastomers provide the elastic component of the asphalt binder and provide an increase in the binder stiffness at high temperature and loading. In contrast, plastomers provide an increase in the binder's stiffness at high temperature and loading, but without an increase in the elastic component of the binder [59]. Generally, plastomeric polymers can improve rut resistance, but they are inferior to elastomers due to the lack of improvements in fatigue resistance, cracking resistance [60] and low-temperature performance. However, elastomers are limited to improve heat resistance.

Asphalt binders containing epoxy polymers are elastomers, also called thermosetting polymers and used to improve some properties of the asphalt blend. For instance, the paving layer on the steel bridge deck endure larger deform and higher temperature. So, some polymers were used to prepare modified asphalt concrete for such purpose. However, neither plastomeric nor elastomeric modified asphalt can change the thermoplastic nature of asphalt, in other words they can not prevent the flow of asphalt mixture at high temperatures [61], [62]. In 2009, Jainyeng et al. have carried out a laboratory study using asphalt binders and epoxy resin elastomers in combination for resolving the abovementioned problems. Epoxy asphalt is prepared by mixing flowed asphalt with certain percentage of SBS copolymers. Then, appropriate amount of curing agent (certain ratio by mass of curing agent to epoxy resin must be used) were added into the blend and mixed strongly. Desired amount of a preheated epoxy resin was added into the blend Results have shown that asphalt in epoxy asphalt has a little effect on the optimum ratio of curing agent to epoxy resin. Fluorescent microscope indicated that epoxy resin was dispersed in asphalt when the epoxy resin content was less than $30 \%$ by weight. The epoxy asphalt began forming networks structure when $30 \%$ by weight epoxy resin blend with asphalt. In addition, the epoxy resin phase gradually became the principle phase with epoxy resin contents continuously increasing. Epoxy asphalt can be cured not only at $120^{\circ} \mathrm{C}$ but also at $60^{\circ} \mathrm{C}$. The initializing viscosity of epoxy asphalts was about (600-800) $\mathrm{mPa}$ s, it was not more than 2 $\mathrm{Pa} \mathrm{s}$ for $60 \mathrm{~min}$ at $120{ }^{\circ} \mathrm{C}$. The change of viscosity attained was due to the appropriate epoxy asphalt mixture blending and compacting. Mechanical properties showed the increase 
of tensile strength when the contents of epoxy resin were more than $30 \mathrm{wt} \%$, due to the formation of continuous networks structure in epoxy asphalt. But the elongation at break of epoxy asphalt decreased as epoxy resin concentration increased [1].

Another common use of elastomeric asphalt binders are those containing SBS copolymer. In an earlier study, A. Adedeji, et al., (1996) have blended SBS tri-block copolymer while they have varied the asphalt composition from $0.0 \%$ to $96.0 \%$ by weight using two types of methods. The first method is called solution casting, where stock solutions of asphalt and SBS in non-selective solubilizing tri-chloroethane were all mixed, and the second type is called the melt process where the samples were made in batch mixer at $200{ }^{\circ} \mathrm{C}$. Result showed that asphalt has solubilized partially the poly-butadiene (PB) mid-block of the SBS to produce saturated (PB) micro-domains network along with the macro-domains network of asphalt. The last was confirmed by stress relaxation tests and actually formed by phase separation of asphalt as large domains in a continuous matrix of SBS rich region, while its concentration varied from $10 \%$ to $90 \%$. The macro-network will break down as the asphalt composition exceeds 90\%. Examination by transition electron microscope (TEM) of the interior of SBS rich regions discovered the micro-domains of asphalt-swollen $\mathrm{PB}$ mid-block with swollen PS micro-domains which its shape was transformed from short cylinders to finally spheres. Dynamic mechanical spectroscopy, (DMS) and differential scanning calorimetry (DSC) analysis indicated a systematic increase in the PB glass transition temperature $\left(T_{g}\right)$ and a negligible change in the $\left(T_{g}\right)$ of the PS as the asphalt content increase. Apparently, tri-block copolymers that can form a macro-network at low concentration seem to be more desirable for highway pavement modifications [63]. Further findings of another study [64] have been carried out on the basis of stress controlled fatigue testing at $20{ }^{\circ} \mathrm{C}$ and $0{ }^{\circ} \mathrm{C}$ indicating that SBS exhibited a better fatigue property when compared to unmodified AC-5 Asphalt (ordinary asphalt/base asphalt). Whereas, other studies have found out that a significant increase in the tensile strength at $21{ }^{\circ} \mathrm{C}, 25$ ${ }^{\circ} \mathrm{C}$ and $41{ }^{\circ} \mathrm{C}$ [12], an elongation in lifetime, and increase in resistance to low temperature cracking [65] of SBS modified asphalt mixes as compared to unmodified asphalt mix.

\section{B. Compatibility in Polymers Blending with Asphalt Case Studies}

Polymers from plastic solid wastes combine the advantages of reducing cost as well as management problem for asphalt industries and producing better asphalt pavement. Further, polyolefin such as PE or PP polymers (either from virgin material or recycled waste) comprise approximately $60 \%$ of plastic solid wastes. Therefore, it is apparent that polyolefin would be more economical and effective in asphalt paving than other polymeric materials. However, not all plastic solid wastes are compatible with asphalt matrix. Asphalt is thermoplastic material of hydrocarbons including paraffinic saturates, aromatics, resins, and graphitic asphaltenes [66]. Therefore, it is an interesting challenge for polymer, which is compatible with asphalt.

Compatibility of asphalt cement (AC) with the admixed polymer is the most important factor in polymer blending with asphalt. One of the many techniques to overcome the incompatibility is the utilization of chemical modification of polymer addition to enhance the interaction of the amorphous region of the polymer with asphalt phase. In this trend, many studies were established. The research of Yu-Hsun Nien et al. (2008) has involved asphalt paving material containing chlorinated polypropylene (CPP) through a wet mix process [67]. The asphalt was preheated first at $180{ }^{\circ} \mathrm{C}$ in a small container and the polymer was added into the container while blend was mixed with a high shear mixer. Results and data analysis, some of which were obtained by using differential scanning calorimetry (DSC) revealed that phase separation occurring in asphalt iso-tactic polypropylene blend (asphalt-iPP) has disappeared because of the amorphous property of the CPP with $26 \%$ by weight of chlorine; this showed more compatibility, led to a higher viscosity in terms of higher temperature to get Newtonian behavior and display also superior rutting resistance to avoid permanent deformation at high temperature. However, increasing chlorine content in CPP with $32 \%$ by weight of chlorine has decreased the viscosity lower than asphalt-iPP blend. In a similar approach, Pei-Hung Yeh et al. (2008) have used polyethylene modifiers characterized with different extent of polarity and hence different amorphous regions; the higher in polarity the more amorphous become. It is a characteristic which is desirable in terms of interaction with the asphalt phase. Results of DSC have shown that asphalt binders containing polyethylene-grafted-maleic anhydride (MPE) was better in interaction with the asphalt phase than LDPE and HDPE, due to the higher dispersion of the higher amorphous content of such polymer into the binder matrix. Rheological studies showed that most of the asphalt blend had superior performance at higher temperature with increasing the contents of those mentioned modifiers such as enhancing rutting resistance as well as frequency of loading and improving creep resistance than conventional asphalt [66]. Back in the early 1990`s a research have been carried out by Labib, M. E. et al., to achieve proper dispersion of CR particulates into asphalt and to make CR compatible modified asphalt with improved, both in high and low temperature properties which can lead to reduced cracking, rutting, and reveling tendencies of the CRMA pavement. The approach to the compatibility was to join the CR and asphalt molecules with small bi-functional molecules (compatibilizers). The CR compatible asphalt was prepared from heating asphalt at $163{ }^{\circ} \mathrm{C}$, followed by the addition of the compatibilizer having the epoxy ring with a glycidyl back bone to the asphalt with continuous stirring. Then CR (6 $15) \%$ was dispersed into the hot asphalt compatibilizer mixture with continuous stirring and heating. The use of a compatibilizer can enhance the solubility of CR into asphalt and improve the rheological properties of CRM asphalt. Modified compatible asphalt is advantageous over the ordinary one by having a wider useful temperature range. The use of modified compatible asphalt has the potential to prevent asphaltic pavement from raveling and may increase the use of scrap tires. The amount of compatibilizer used in asphalt is dependent on the source of asphalt [10], [68].

Although, polymers additions to asphalt leads to improvements in properties of polymer modified asphalt, 
they usually increases the cost of asphalt. Plastic solids such as polyethylene and polypropylene which comprises the major constituents, however either from fresh raw materials or waste recyclable ones, were not all compatible with the asphalt matrix. And hence, alternatives were investigated and studies were reported:

\section{Blending of Asphalt with Crumb Rubber Tires}

Several studies referred to the benefit of using tire rubbers in asphalt mixtures; it provides rubberised asphalt with better skid resistance, reduced fatigue cracking, improved resistance to rutting, improved tensile strength and toughness, longer pavement life and reduced maintenance costs compared with conventional mixtures [32], [69]-[73]. Rubberised asphalt mixtures show better performances at high temperatures, they can be used in a variety of climate conditions and are more flexible at low and sub-under zero temperatures, while the thickness of an asphalt layer can be reduced from 50 to $38 \mathrm{~mm}$ [74]. Besides, rubberized asphalt concrete is cost effective, saving as much as $\$ 22000$ per lane mile over conventional asphalt projects [75]. This market for worn vehicle tires can consume large quantities of scrap tires in a positive manner.

The use of asphalt rubber pavements enhances a number of engineering properties of the asphalt mixture, but many variables such as amount of $\mathrm{CR}$, reaction time and temperature affecting the blending process must be controlled and optimized. The gradual change in viscosity of the binder has been used to indicate the progress of the interaction between asphalt and rubber. Early laboratorial tests carried out by Green \& Tolonen (1977) have emphasized the importance of controlling the swelling processes through controlling the interaction time and temperature. In their laboratorial study, they also have concluded that temperature has two effects on the blending process. The first effect was on the rate of swelling of rubber particles; as the temperature increases, the rate of swelling increases. The second effect was on the extent of swelling; as the temperature increases, the extent of swelling decreases [76], [77]. Oliver (1982) has reported that the time and temperature of digestion of CR with asphalt were known to have an important effect on the resulting CRA. The major effect was probably absorption of aromatic oils by the rubber particles in the asphalt. As a result, this caused softening and swelling of the rubber particles and a comparatively large proportion of the binder consisted of soft rubber. At the same time, the asphalt phase hardened. These were all physical changes [77], [78].

Lately, the study of Rokade S., (2012) [3] have been accomplished through the use of waste plastics LDPE and CR blended with asphalt using dry process and wet process respectively. The study involved the use of Marshal method of asphalt mix design to determine the different mix of LDPE and CR and their effect on the design characteristics. Results have revealed that the Marshal stability value, which is the strength parameter of semi dense asphalt concrete have increased by $25 \%$ as LDPE and CR increased. Density of the mix has also increased in both cases when compared with virgin commercial asphalt, providing more stable and durable mix for the flexible pavements. Results and values of air voids, voids in mineral aggregate and voids filled with asphalt were found out to be within required specifications. Researchers have concluded also that waste plastics and CR's will be of great benefits particularly to those hot and extremely humid climate countries. It was also worth mentioning that in the modified process (dry process) waste plastics are coated over aggregate. This was assumed to help a better binding between the asphalt and coated aggregates due to the increase in bonding and area of contact. This will therefore decrease in voids preventing the moisture absorption and oxidation (by air/water) of the asphalt. Chui-Te Chiu and Li-Cheng Lu, (2007) have used asphalt rubber, produced by blending ground tire rubber (GTR) i) $30 \%$ of a coarse GTR with a maximum size of \#20 sieve and ii) $20 \%$ of a fine with a maximum size of \#30 sieve with an asphalt, as a binder for SMA and found AR-SMA mixtures were not significantly different from conventional SMA in terms of moisture susceptibility and showed better rutting resistance than that of conventional dense graded mixture [79]. A set of laboratorial tests were done using CR, obtained by ambient grinding, with conventional asphalt commercially named CAP-50/70. The set of tests includes the following: i) penetration; ii) softening point; iii) resilience; iv) apparent viscosity. From these tests, the following were concluded: i) the penetration decreased as the amount of rubber increased up to $21 \%$ for only $60 \mathrm{~min}$ reaction time, then the heavier of $21 \%$ was varied due to the increase of viscosity; ii) up to $21 \%$ $\mathrm{CR}$ amount, the softening point increased and were similar for 30, 45 and 60 min reaction time; iii) the resilience results were influenced mainly by the amount of CR added, and the reaction time had no influence in the change of asphalt properties, on the other hand, addition of CR increased the elasticity; iv) in a major way, the amount of CR added has influenced the viscosity of the final product, and exceeded the standards when more than $21 \%$ was added [77]. Another laboratory investigations was conducted on the asphalt binder properties as a function of various blending treatments (temperatures and times), and the CRM percentages. CRM binders were produced through an accelerated un-aged binder process by using the three binder tests (penetration test, viscosity test, softening point test). The result from this study showed that: i) blending interaction times and blending interaction temperatures for CRM binders had effects on the binder properties; ii) the longer time and higher temperature for interaction of CRM binder's resulted in an increase in viscosity, and softening point; iii) the CRM percentage decreased the penetration, which would enhance CRM binder stiffness, and asphalt binder consistency and resistance to flow, which led to improve rutting resistance. However, this study found that control binder of $80 / 100$ grad penetration had little change of the binder properties as a function of interaction blending conditions [80]. Shankar et al., (2009), have carried out a study on blending CRM asphalt (CRMB 55) at specified temperatures. Marshall's mix design was done by changing the modified asphalt content at constant optimum rubber content. Subsequent tests have been performed to determine the different mix design characteristics for CRMB 55 as well as the conventional asphalt (60/70). This has resulted in much improved characteristics when compared with virgin asphalt. The same was also obtained at a reduced optimum modified binder 
content of $5.67 \%$ [81].

\section{CONCLUSION}

This review intended to provide interested readers with the significance of recycling the SIW; it is considered as one of the greatest problems facing the rubber industry today. Our review focused on SIW represented by rubber tires and plastics as tow very effective modifiers for the improvements of asphalt pavement material. The blending of recycled waste rubber tires in the form of CRs and plastics with the asphalt requires a number of experimental factors to be controlled and various techniques to be selected in order to reach improvement in engineering properties of asphalt binder. The number of case studies supplied throughout this paper was sufficient to help readers to be familiar with the different technologies applied of producing and incorporating modifiers in asphalt mixtures that are important in construction of roads with very qualified pavements and improved longevity and pavement performance.

\section{REFERENCES}

[1] J.-Y. Yu, P.-L. Cong, and S.-P. Wu, "Laboratory Investigation on the Properties of Asphalt Modified with Epoxy Resin," Journal of Applied Polymer Science, vol. 113, pp. 3557-3563, 2009.

[2] M. Sienkiewicz, J. K. Lipka, H. Janik, and A. Balas, Waste Management, vol. 32, 2012.

[3] S. Rokade, "Use of plastic and waste rubber tires in flexible highway pavements," in Proc. International Conference on Future Environment and Energy, vol. 28, IACSIT Press, Singapoore, 2012.

[4] D. D. Carlson and H. Zhu, "Asphalt-Rubber - An Anchor to Crumb Rubber Markets," in Proc. Third Joint UNCTAD/IRSG Workshop on Rubber and the Environment, International Rubber Forum, Veracruz, Mexico, October 7, 1999

[5] B. Prusty, "Use of waste polyethylene in bitminous concrete mixes," A Thesis Submitted in Partial Fulfillment of the Requirements for the Degree of Bachelor of Technology in "Civil Engineering", Department of Civil Engineering, NIT Rourkela, National Institute of Technology, Rourkela-769008 (ODISHA), May 2012

[6] R. E. Winters, "The conception and development of asphalt rubber," presented at the National Seminar on Asphalt Rubber, Kansas City Missouri-USA, October 1989.

[7] J. E. Huffman, "Sahuaro concept of asphalt-rubber binders," presented at the First Asphalt Rubber User Producer Workshop, Scottsdale Arizona-USA, May 1980.

[8] J. A. Epps and B. M. Galloway, (1980), "First Asphalt-Rubber," User-Producer Workshop Proceedings Summary, May 1980.

[9] B. Brule, "Polymer-modified Asphalt contents used in the road construction industry: basic principles," Transportation Research Record: J. Transport. Res. Board, vol. 1535. pp. 48-53, 1996.

[10] S. Marvridou, N. J Oikonomou, and A. A Kalofotias, "Integration of end-of-life tires in the life cycle of road construction," EU-LIFE+ Environment Policy and Governance, LIFE 09 ENV/GR/304 “ROADTIRE”, Thessaloniki, December 2010.

[11] F. L. Roberts, P. S. Kandhal, E. R. Brown, and R. L. Dunning, "Investigation and evaluation of ground tire rubber in hot mix asphalt," National Center for Asphalt Technology, NCAT Report No. 89-3, 1989.

[12] ASTM (American Society for Testing and Materials), International Annual Book of Standards, D 8 Definitions, 2005.

[13] P. E. L. Santucci, "Rubber roads: waste tires find a home, pavement technology update," Technology Transfer Program, vol. 1, issue. 2 , Sep. 2009.

[14] G. D. Airey, A. C. Collop, and T. M. Singleton, "Rheological and cohesive properties of bitumen cured in crumb rubber," in Proc. the International Symposium of Concrete Technology, University of Dundee, 2001, pp. 281-298.

[15] N. Oikonomou and S. Mavridou, "The use of waste tire rubber in civil engineering works," in Sustainability of Construction Materials, J. Khatid, Ed. ch. 9, Woodhead publishing, 2009a, pp. 213-238.

[16] J. C. Pais, J. B. Sousa, R. Saam, and P. A. A. Pereire, "Effect of crumb rubber origin on asphalt hot mix laboratory performance," in Proc. $2^{\text {nd }}$ International Symposium on Maintenance and Rehabilitation of
Pavements and Technological Control, 29 July - 1 August 2001, Auburn, AL, USA, pp. $1-10$.

[17] V. S. Punith, M. N. Thyagaraj, and A. Veeraragavan, "Studies on tensile strength characteristics of dense bituminous macadam mix with crumb rubber as modifier," in Proc. the $3^{\text {rd }}$ International Conference on Bituminous Mixtures and Pavements, Thessaloniki, Greece, 2002, pp. 547-556.

[18] M. M. Rahman, G. D. Airey, and A. C. Collop, "Laboratory investigation to assess moisture sensitivity of dry process CRM asphalt mixtures," in Proc. the International Conference Organized by the Concrete and Masonry Research Group, 2004, pp. 151-162.

[19] A. Tortum, C. Celik, and A. C. Aydin, "Determination of the optimum conditions for tire rubber in asphalt concrete," Building and Environment, vol. 40, pp. 1492-1504, 2005.

[20] C.-T. Chiu, "Use of ground tire rubber in asphalt pavements: field trial and evaluation in Taiwan," Resources, Conservation and Recycling, vol. 52, no. 3, pp. 522-532, 2008.

[21] B. Choubane, G. A. Sholar, J. A. Musselman, and G. C. Page, "Ten-year performance evaluation of asphalt-rubber surface mixes," Transportation Research Record, pp. 10 - 18, 1999.

[22] Ruber Pavement. [Online]. Available: http://www.ruberpavement.org

[23] J. L. Fernandes Jr., S. A. M. Bertollo, L. L. B. Bernucci, and E. de Moura, "Laboratory evaluation of dense asphalt mixtures modified with addition of rubber," in Proc. 3rd International Conference on Bituminous Mixtures and Pavements, J\&A Publishers, Thessaloniki, Greece, 2002.

[24] Rubber Rise Dasphalt. [Online]. Available: http://www.rubberisedasphalt.org

[25] H. A. Khalid and I. Artamendi, "Exploratory study to evaluate the properties of rubberized asphalt modified using the wet and dry processes," in Proc. 3rd International Conference on Bituminous Mixtures and Pavements, $J$ \& A Publishers, Thessaloniki, Greece, 2002, pp. $15-25$.

[26] G. D. Airey, M. M. Mujibur, and A. C. Collop, "Absorption of bitumen into crumb rubber using the basket drainage method," International Journal of Pavement Engineering, vol. 4, no. 2, pp. 105-119, 2003.

[27] R. Kettab and A. Bali, "Modified bituminous concrete using rubber powder," in Proc. the International Conference Organized by the Concrete and Masonry Research Group, Kingston University, London, Thomas Telford, 2004, pp. $163-170$.

[28] N. Oikonomou, S. Mavridou, and A. Kazakpoulos, "Study of asphalt mixtures modified with tire rubber," in Proc. the $4^{\text {th }}$ International Conference on Bituminous Mixtures and Pavements, Thessaloniki, Greece-Greek, vol. 1, 2007, pp. 465-477.

[29] N. Sunthonpagasit and M. Duffey, "Scrap tires to crumb rubber: Feasibility analysis for processing facilities," Resource Conservation and Recycling Journal, vol. 40, pp. 281 - 299, March 2004.

[30] CWC, "Best practices in scrap tires \& rubber recycling: ambient versus cryogenic grinding," Clean Washington Centre, Best Practice Document BP-T2-03-04, 1998.

[31] K. Reschner. (2008). Scrap tire recycling; a summary of prevalent disposal and recycling methods. [Online]. Available: http://Reschner@EnTire-Engineering.de

[32] S.-J. Lee, C. K. Akisetty, and S. N. Amirkhanian, "The effect of Crumb Rubber Modifier (CRM) on the performance properties of rubberized binders in HMA pavements," Construction and Building Materials Journal, vol. 22, pp. 1368 - 1376, 2008.

[33] B. J. Putman, J. U. Thompson, S. N. Amirkhanian, "High-temperature properties of Crumb Rubber Modified (CRM) Asphalt Binders," in Proc. Fourth International Conference on Maintenance and Rehabilitation of Pavements and Technological Control (MAIREPAV4), Belfast, Northern Ireland, 2005.

[34] H. U. Bahia and R. Davis, "Effect of Crumb Rubber Modifiers (CRM) on performance related properties of asphalt binders," Journal of the Association of Asphalt Paving Technologists, vol. 63, pp. 414-449, 1994.

[35] B. Huang, L. N. Mohammad, P. S. Graves, and C. Abadie, "Louisiana experience with crumb rubber-modified hot-mix asphalt pavement," Transportation Research Record: Journal of the Transportation Research Board, no. 1789, vol. 1-13, 2002.

[36] S.-J. Lee, S. Amirkhanian, B. J. Putman, and K. W. Kim, "Laboratory Study of the effects of compaction on the volumetric and rutting properties of CRM asphalt mixtures," Journal of Materials in Civil Engineering, ASCE, vol. 19, no. 12, pp. 1079-1089, 2007.

[37] R. Y. Liang and S. Lee, "Short-term and long-term aging behavior of rubber modified asphalt paving mixtures," Transportation Research Record: Journal of the Transportation Research Board, no. 1530, pp. 11-17, 1996.

[38] M. Blumenthal and J. Serumgard, "Overview of scrap tire management and markets in the United States," in Proc. A Meeting of the Rubber 
Division in Orlando, Florida, American Chemical Society, September 1999.

[39] F. P. Xiao and S. N. Amirkhanian, "Resilient modulus behavior of Rubberized Asphalt Concrete (RAC) mixtures containing Reclaimed Asphalt Pavement (RAP)," Road Materials and Pavement Design, 2007.

[40] S. Amirkhanian and M. Corley, "Utilization of rubberized asphalt in the United States: an overview," in Proc. $4^{\text {th }}$ International Symposium Advanced Technologies in Asphalt Pavements, South Korea, 2004, pp. 3-13.

[41] A. Jamishidi, M. O. hamzah, and Z.-P. You, "Performance of warm mix asphalt containing sasobitt: State-of-Art," Constr .Build Mater J. l, vol. 38, pp. 530-553, 2013.

[42] L. A.-Q. Imad, J. Baek, Z. Leng, H. Wang et al., "Short-term performance of modified Stone Matrix Asphalt (SMA) produced with warm mix additives," A Report of the Findings of Early-Age Deformation/Rutting of Modified Stone Matrix Asphalt (SMA) Produced with Warm Mix Additives Project, Illinois Center for Transportation, USA, January 2012

[43] C. K. K. Akisetty, "Evaluation of warn asphalt additaives on performance properties of crumb binders and mixtures," Dissertation, the Graduate School of Clemson University, Partial Fulfillment of the Requirements for the Degree Doctor of Philosophy - Civil Engineering, p. 13, August 2008.

[44] A. Chowdhury and J. W. Button, "A review of warm mix asphalt," Report 473700-00080-1, Texas Transportation Institute, College Station, Texas, 2008.

[45] B. D. Prowell, G. C. Hurley, and E. Crews, "Field performance of warm-mix asphalt at national center for asphalt technology test track," Transportation Research Record, no. 1998, Washington, D.C., pp. 96-102, 2007.

[46] N. M. Wasiuddin, S. Selvamohan, M. M. Zaman, and M. L. Guegan, "Comparative laboratory study of sasobit and aspha-min additives in warm-mix asphalt," Transportation Research Record, no. 1998, Washington, D.C., pp. 82-88, 2007.

[47] R. B. Mallick, P. S. Kandhal, and R. L. Bradbury, "Using warm-mix asphalt technology to incorporate high percentage of reclaimed asphalt pavement material in asphalt mixtures," Transportation Research Record, no. 2051, Washington, D.C., pp. 71-79, 2008.

[48] S. J. Lee, C. K. Akisetty, and S. N. Amirkhanian, "The effect of Crumb Rubber Modifier (CRM) on the performance properties of rubberized binders in HMA pavements," Constr. Build. Mater. J., vol. 22, no. 7, pp. 1368-1376, 2008.

[49] F. Xiao, S. N. Amirkhanian, and B. Putman, "Evaluation of rutting resistance in warm-mix asphalts containing moist aggregate," Transportation Research Record, Washington, D.C., no. 2180, pp. 75 $84,2010$.

[50] G. C. Hurley and B. D. Prowell, "Evaluation of Aspha-Min ${ }^{\circledR}$ zeolite for use in warm mix asphalt," Report NCAT 05-04, National Center for Asphalt Technology, Auburn University, Auburn, Alabama, 2005a.

[51] G. Hurley and B. D. Prowell, "Evaluation of sasobit ${ }^{\circledR}$ for use in warm mix asphalt," NCAT Report 05-06, National Center for Asphalt Technology, Auburn University, Auburn, Alabama, 2005b.

[52] G. Hurley and B. D. Prowell, "Evaluation of evotherm ${ }^{\circledR}$ for use in warm mix asphalt," NCAT Report 06-02, National Center for Asphalt Technology, Auburn University, Auburn, Alabama, 2006.

[53] E. R. Brown, J. E. Haddock, R. B. Mallick, and A. T. Lynn, "Development of a mixture design procedure for Stone Matrix Asphalt (SMA)," NCAT Report No. 97-3, 1977.

[54] A. Gawande, G. Zamare, V. C. Renge, S. Tayde, and G. Bharsakale, "An overview on waste plastic utilization in asphalting of roads," Engineering Research and Studies Journal, vol. III, no. II, pp. 1-5, 2012.

[55] R. S. Shukla and P. K. Jain, "Improvement of waxy bitumen by the addition of synthetic rubbers, poylmer and resins," Highway Research Bulletin, Indian Roads Congress, Delhi, pp. 17 - 28, 1984.

[56] C. E. G. Justom and A. Veeraragavan, "Utilization of waste plastic bags in bituminous mix for improved performance of roads," Centre for Transportation Engineering, Bangalore University, Bangalore, India, 2002.

[57] T. A. Mohammad and S. Lina, "The use of polyethylene in hot asphalt mixtures," American Journal of Applied Sciences, vol. 4, no. 6, pp. 390 - 396, 2007.

[58] G. Malarvizhi, N. Senthul, and C. Kamaraj, "A study on Recycling of crumb rubber and low density polyethylene blend on stone matrix asphalt," Inter, J. Sci. Res., vol. 2, no. 10, 2012.

[59] P. E. P. Lavin. (2003). Binder performance. Winter Haven. [Online]. Available: http://www.ARR-MAZ.com
[60] Z. Vlachovicova, C. Wekumbura, J. Stastna, and L. Zanzotto, "Creep charactristics of asphalt modified by radial styrene-butadiene-styrene copolymer," Constr. Build. Mater. J., vol. 21, pp. 567-577, 2007.

[61] B. Yvonne, J. Aljendro, and R. Yajarira, "Use of rheological compatability criteria to study sbs modified asphalt," J. Appl. Polym. Sci, vol. 90, no. 3, pp. 1772-1882, 2003.

[62] W. G. Wong, H.-F. Han, G.-P. He, K. C. P. Wang, and W.-M. Lu, "Rutting response of hot mix asphalt to generalized dynamic shear moduli of asphalt binder," Const Buil Mater J., vol. 18, no. 6, pp. 399-408, 2004

[63] A. Adedeji, T. Grunfelder, F. S. Bates et al., "Asphalt modified by tri-block copolymer: structures and properties," Polymer Engineering \& Science, vol. 36, no. 12, pp. $1707-1723,1996$.

[64] T. S. Shuler, J. H. Collins, and J. P. Kirkpatrick, "Polymer modified asphalt properties related to asphalt concrete performance," in Asphalt Rheology Relationship to Mixture ASTM, STP 941, O. E. Briscoe, Ed. ASTM: Philadelphia, 1987.

[65] J. H. Collins, M. G. Bouldin et al., "Improvement performance of paving asphalt by polymer modification," Pro. Asso. Asphalt Paving Techol., vol. 60, 1991.

[66] P.-H. Yeh, Y.-H. Nien, W.-C. Chen, and W.-T. Liu. (2008). Evaluation of thermal and viscoelastic properties of asphalt binders by compounding with polymer modifiers. Wiley InterScience. [Online] Available: http:// www.interscience.wiley.com

[67] Y.-H. Nien, P.-H. Yeh, W.-C. Chen, W.-T. Liu and J.-H. Chen. (2008) Investigation of flow properties of asphalt binders containing polymer modifiers. Wiley InterScience. [Online]. Available: http://www.interscience.wiley.com

[68] M. E. Labib, G. M. Memon, and B. H. Cholla, Compatabilizers for Crumb Rubber Modified Asphalt, Orlanado, pp. 1209-1213, 1993.

[69] N. P. Khosla and J. T. Trogdon, "Use of ground rubber in asphalt paving mixtures,” Technical Report, Department of Civil Engineering, North Carolina State University, Raleigh, 1990.

[70] G. D. Airey, A. C. Collop, and M. M. Mujibur, "Mechanical properties of crumb rubber modified asphalt mixtures," in Proc. 3rd Eurasphalt \& Eurobitume Congress, Vienna, 2004.

[71] I. Widyatmoko and E. Richard, "A review of the use of crumb rubber modified asphalt worldwide," Final Draft, Pro Testing to UK Standards, 2008

[72] D. G. Goulias and A. H. Ali, “Asphalt rubber mixture behavior and desprocess," Journal of Testing and Evaluation, Americ Society of Testing Materials, West Conshohocken, PA, vol. 26, no. 4, pp. 306-314, 1998

[73] D. G. Goulias and A. Ntekim, "Durability of asphalt mixtures with recycled tire rubber," Journal of Solid Waste Technology and Mangaments, vol. 27, no. 3\&4, pp. 170-174, Philadelphia, PA, 2001.

[74] Ruberized Asphalt. [Online]. Available: http:/ www.ruberizedasphalt.org

[75] Department of Public Works. [Online]. Available: http:// ladpw.org/epd/tirerecycling/RAC-REAS.cfm

[76] M. Abdeirahman, "Controlling the performance of Crumb Rubber Modifier (CRM) binders through the addition of polymer modifiers," in Proc. 85th Annual Meeting of the Transportation Resesarch Board, Washington, DC, USA, 2006.

[77] P. A. A. Pereira and J. C. Pais, "Laboratory optimization of continous blend asphalt rubber," in Proc. the $3^{\text {rd }}$ European Pavement and Asset Management EPAM 3. Coimbra, 2008, vol. 1, pp. 1-12.

[78] J. W. H. Oliver, "Optimizing the improvements obtained by the digestion of comminuted scrap rubber in paving asphalts," in Proc. Assoc. Asphalt Paving Tech., vol. 51, pp. 169-188, 1982.

[79] C.-T. Chiu and L.-C. Lu, "A laboratory study on stone matrix asphalt using ground rubber," Constr. and Build. Mater. J., vol. 21, no. 5, pp. 1027-1033, 2007.

[80] N. S. Mashaan, M. R. Karim, A. H. Ali, and M. A. Aziz, "Influence of blending interaction of crumb rubber modified biitumen on pavement properties," in Proc. Malaysian Universities Transportation Research Forum and Conferences 2010 (MUTRFC2010), Universiti Tenaga Nasional, 21 December 2010.

[81] S. Shankar and C. K. Prasad, "Evaluation of rutting potential for crumb rubber modified bitumen in asphaltic mixes," Emirates Journal for Engineering Research, vol. 14, no. 2, pp. 91-95, 2009.

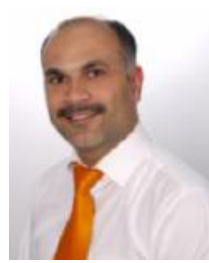

Mohamed Sulyman got MSc. degree in the field of chemical engineering \& petroleum, from Academy of Graduate Studies in Tripoli-Libya in 2008 and B.Sc. degree in chemical engineering from Al-Mergheb University in Libya 2000. He was born in 1976 in Libya. Currently he is a $\mathrm{PhD}$ student at Chemical Faculty of the Gdansk University of Technology in Poland. His major field of study is polymer technology. 
His area of research is chemical engineering \& polymers. His main related topic is new study on improved performance of paving asphalts by crumb rubber and polyethylene modification.

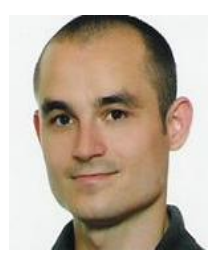

Maciej Sienkiewicz obtained his Ph.D. in 2010 from the Chemical Faculty, Gdansk University of

Technology, Poland, with a thesis entitled "Polyurethane-rubber composites obtained from rubber recyclates, as a method for disposal of waste tires". He is employed at the Polymer Technology Department, at the Chemical Faculty Gdansk University of Technology since 2011, currently as an assistant professor. His research interests include especially polyurethane materials and recycling of waste tires. His current work is focused on the development of new environmentally friendly polyurethane-rubber composites with reduced manufacturing costs, derived from polyurethanes (foams and elastomers) and rubber granulates, obtained from recycled waste tires. His research work also includes studies on the search for new solutions in polymer-modified asphalts, especially asphalts modified by polymeric materials obtained during recycling of waste tires.

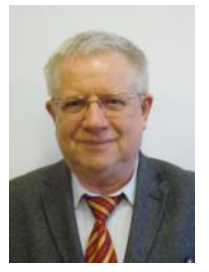

Jozef Haponiuk was born in 1950. He obtained his PhD title in 1979 from the Technische Hochschule Leuna Merseburg, Germany. Since 2006 he is the head of Department of Polymer Technology at the Chemical Faculty of the Gdańsk University of Technology. His special scientific interest are chemistry, characterization and processing of polyurethanes, recycling of polymers and rubbers, biobased polymers, polymer composites and nanocomposites. 